\title{
QUALIDADE NA EDUCAÇÃO SUPERIOR: LUGAR E SENTIDO NA RELAÇÃO PÚBLICO-PRIVADO
}

\author{
José Vieira de Sousa*
}

RESUMO: Este artigo discute a temática "qualidade na educação superior", problematizando-a no âmbito da relação público-privado. A tese defendida é de que, no Brasil, historicamente, a política educacional promoveu restrição do público e estímulo à iniciativa privada nesse nível de educação. O debate considera os cenários do país e do Distrito Federal, neste último tomando como referência estudo realizado em um grupo de instituiçóes de educação superior locais. A discussão chama a atenção para a polissemia e complexidade do conceito de qualidade, a heterogeneidade institucional do sistema brasileiro de educação superior e a centralidade do binômio avaliação/qualidade como política pública para o setor.

Palavras-chave: Educação superior. Qualidade. Relação público-privado. Distrito Federal.

Higher EDUCATION QUALITY:

PLACE AND MEANING OF THE PUBLIC-PRIVATE RELATIONSHIP

ABSTRACT: Based on the public-private relationship context, this paper discusses higher education quality. It advocates that, in Brazil, educational policies have historically promoted restriction to public initiative and encouraged the private initiative for this education level. It considers both the national scenery and that of the Distrito Federal according to a study on a local group of higher education establishments. The discussion points out the different meanings and complexity of the concept of quality, the

Doutor em Sociologia e professor adjunto da Faculdade de Educação da Universidade de Brasília (UnB).E-mail: sovieira@fe.unb.br 
institutional heterogeneity of the Brazilian higher education system, and the centrality of the binomial evaluation/quality as a public policy for the sector.

Key words: Higher education. Quality. Public-private relationship. Distrito Federal.

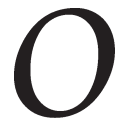

presente artigo tem como objetivo discutir a temática "qualidade na educação superior", problematizando-a no âmbito da relação público-privado. A reflexão parte da premissa de que, no Brasil, historicamente, a política educacional promoveu restrição do público e estímulo à iniciativa privada nesse nível de educação. $\mathrm{O}$ debate proposto considera, ao mesmo tempo, dois cenários: o nacional e do Distrito Federal (DF). Neste último, toma como referência estudo realizado em um grupo de dezesseis instituições de educação superior (IES) locais.

Estruturalmente, o texto apresenta três partes. Na primeira, chama-se a atenção para a polissemia e complexidade do conceito de qualidade, particularmente quando associado à questão educacional. Em seguida, aborda-se a heterogeneidade institucional do sistema brasileiro de educação superior e a centralidade da avaliação como política pública para o setor. $\mathrm{Na}$ terceira parte, apresentam-se os aspectos metodológicos da pesquisa, bem como os resultados do estudo, considerando as percepções expressas por um grupo de gestores de instituiçôes de educação superior do DF relativos à temática.

Qualidade: uma palavra, vários sentidos

O conceito de qualidade está envolto por uma gama de polêmicas e lógicas. Enguita (1995) problematiza esse conceito, conforme três lógicas: a) qualidade associada à ideia de "bem-estar", entendido como o bem comum e expresso sob todas as formas de satisfação das necessidades coletivas; b) qualidade vinculada à eficácia dos processos, representando o alcance do máximo de resultados com o mínimo de custo e atendendo à lógica da produção privada; c) qualidade ligada à competição de mercado que, no momento atual, tem sido tomada, por diferentes instâncias, como referência para manobras governamentais de privatização da educação. 
Em qualquer contexto social, político e econômico, uma determinada concepção de qualidade ganha prevalência sobre as demais sem, contudo, implicar a extinção de outras com as quais convive. Cada nova versão da qualidade não substitui inteiramente, e de uma vez por todas, as anteriores, permitindo que setores e grupos com interesses distintos possam coincidir em torno de uma mesma palavra de ordem (Enguita, 1995).

Com efeito, as definições para a palavra qualidade são inúmeras e mutáveis. Por isso, a transformação é fator essencial para que se compreenda, de forma mais contextualizada e crítica, o seu percurso histórico-social e como ele se deixa construir. Esta preocupação ganha relevo, particularmente, pela carga subjetiva e polissêmica que a palavra qualidade envolve, quando aplicada à educação. Assim, é preciso buscar sucessivas aproximaçóes do conceito, visto que a

(...) a qualidade da educação é um fenômeno complexo, abrangente, e que envolve múltiplas dimensões, não podendo ser apreendido apenas por um reconhecimento de variedade e das quantidades mínimas de insumos considerados indispensáveis ao desenvolvimento do processo ensino-aprendizagem e muito menos sem tais insumos. (Dourado, Oliveira \& Santos, 2007, p. 9)

A própria condição humana leva à procura de algo mais qualitativo. Conforme a área em que é abordado, o sentido de qualidade é construído e utilizado atendendo a padrões concebidos e transformados pelos indivíduos. Nesse nível de entendimento, o conceito em questão é historicamente construído, e sua formulação e compreensão devem considerar as condições específicas e conjunturais da sociedade que possibilitam sua produção - a configuração sociocultural de determinados indivíduos ou grupos de indivíduos.

A qualidade não é um valor absoluto, nem a mera adequação de ideias, processos e práticas a certo padrão ou a normas estabelecidas a priori. Assim, torna-se impossível sua vinculação a um único atributo ou olhar. Para Bondioli (2004), a qualidade precisa ser negociada e, sobretudo, no campo educacional, no decorrer de debates entre sujeitos e grupos que possuam interesse na rede educativa. Em outras palavras, entre indivíduos "(...) que têm responsabilidade para com ela, com a qual estão envolvidos de algum modo e que trabalham para explicitar e definir, 
de modo consensual, valores, objetivos, prioridades, ideias sobre como é a rede (...) e sobre como deveria ou poderia ser" (p. 14).

Do ponto de vista etimológico, qualidade corresponde à propriedade, atributo ou condição das coisas ou das pessoas, capazes de distingui-las das outras e/ou de lhes determinar a natureza. Por sua vez, o termo latino qualitas significa essência e designa o que é mais importante, o que determina algo. Assim, a qualidade indica a centralidade das coisas e dos seres, aquilo que essencialmente caracteriza algo e o marca. Em razão da complexidade que esse conceito envolve, refletir a respeito dele significa lidar com o contraditório e o provisório, reconhecendo que a educação, no mundo atual, recorre constantemente a ele, identificandoo como seu principal objetivo.

\section{Educação superior brasileira: cenários e tendências}

No mundo contemporâneo, a educação é reconhecida como elemento fundamental à formulação das políticas públicas e dos projetos da esfera privada, com um papel essencial no fortalecimento das dimensōes socioeconômicas e culturais (Guadilla, 2002). Ganham destaque, nesse cenário, os sistemas de educação superior, que se configuram como campos construídos mediante embates e lutas acerca de sua interpretação.

No caso do Brasil, o campo da educação superior é bastante heterogêneo, possibilitando identificar em seu interior segmentos institucionais diversos, que possuem características bastante distintas nas esferas pública e privada. Todavia, esse cenário não tem conseguido alterar, em níveis satisfatórios, o discurso marcadamente ideologizado que insiste em tratá-lo como único, quando nele existe uma diversidade de práticas e vocaçóes (Sousa, 2006).

A figura 1, a seguir, apresenta dados relativos à distribuição das IES nas várias regiôes brasileiras, considerando a rede formada por universidades, centros universitários, faculdades integradas, faculdades, escolas, institutos e centros de educação tecnológica, no ano de 2006.

Os dados apresentados revelam uma grande concentração de instituições de educação superior na tipologia de faculdades, escolas e institutos, os quais se vinculam, majoritariamente, ao segmento privado. Todavia, caso se considere apenas o grupo formado por essas 
Qualidade na educação superior: lugar e sentido na relação público-privado

escolas ou, então, aqueles correspondentes às universidades ou às faculdades integradas, é possível constatar, em qualquer um deles, uma diversidade expressiva de perfis e vocaçōes acadêmicas das IES que os compõem, tanto em nível do país como do Distrito Federal.

\section{Gráfico 1}

Distribuição das IES, por categoria administrativa e regiôes (2006)

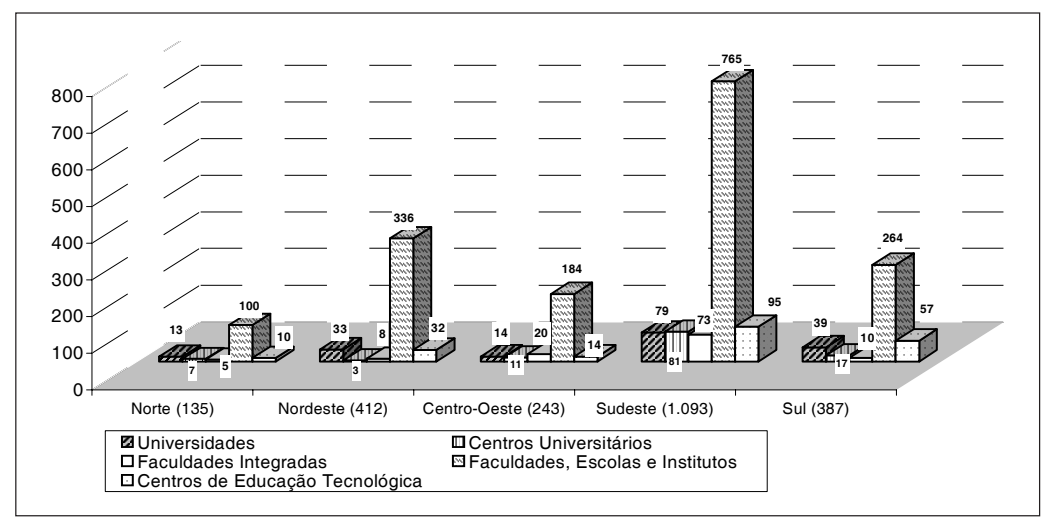

Fonte: Brasil/MEC/INEP/DEAES (2008)

A heterogeneidade institucional e os dilemas atualmente enfrentados pela educação superior brasileira, particularmente quanto à questão da qualidade, suscitam questôes como: a) que lugar e sentido a qualidade assume na relação público-privado, considerando a política educacional definida para o setor?; b) em razão da centralidade assumida pela avaliação, como política pública, a partir da década de 1990, que tendências as IES revelam para o conceito de qualidade?

O sistema brasileiro de educação superior continua a lidar com problemas estruturais, no que tange à democratização do seu acesso. Por outro lado, a preocupação com a necessidade de sua expansão aparece nos artigos 44 e 45 da Lei de Diretrizes e Bases (LDB n. 9.394/96; Brasil, 1996), os quais abrem a possibilidade da existência de outros tipos de instituiçôes que possam vir a oferecer novas modalidades na educação superior. Com efeito, essa lei é um marco da reestruturação 
da educação superior na década de 1990, pois traduziu uma nova forma de ação e de relacionamento entre Estado e IES. Nesse sentido, o Estado assume um papel preponderante no controle e gestão de políticas para o setor, o que ocorre, fundamentalmente, por meio dos mecanismos de avaliação e financiamento. Esta atitude implicou novas formas de conceber a produção do trabalho acadêmico, focalizando o mercado (Oliveira $\&$ Dourado, 2005).

$\mathrm{Na}$ referida década, bem como na atual, o Estado brasileiro não conseguiu garantir à população, de forma satisfatória, o acesso à educação superior pública. A saída adotada pelo governo foi estimular a expansão da educação superior, pela via da rede privada, na perspectiva de garantir aos alunos maior opção, em termos de novos cursos e de IES. O estímulo governamental teria se apoiado na flexibilização apresentada pela Lei n. 9.394/96 e, depois, no próprio Plano Nacional de Educação (PNE, Lei n. 10.172, de 9 de janeiro de 2001), que prevê, como principal meta, elevar a oferta de educação superior para, pelo menos, $30 \%$ da população brasileira na faixa etária de 18 a 24 anos, até o ano de 2010 (Brasil, 2001).

Nesse cenário, ganha relevo a relação público-privado e o papel do Estado na política de privatização da educação superior, visto que, no Brasil, se observa a tendência histórica de restrição do público e estímulo à iniciativa privada (Sousa, 2006). Considerando a realidade do setor público e de uma rede privada em largo processo de expansão nas últimas décadas, o autor formula o seguinte questionamento: “(...) como assegurar um processo de avaliação permanente, que garanta a associação do aumento de vagas no ensino superior à exigência de qualidade do ensino?" (p. 46).

No mesmo quadro, destaca-se avaliação e, consequentemente, a ênfase na qualidade. Em virtude da centralidade que ganhou na educação brasileira, nos anos de 1990, a avaliação tornou-se assumidamente objeto de política pública, traduzindo-se por meio de várias propostas. Em sua essência, tais propostas são construídas em terrenos de embates e disputas, visto que a educação superior se configura em campo de luta que, como qualquer outro, possui um objeto de disputa (Bourdieu, 1990).

De acordo com o referido autor, ao atuar no interior de um campo, os agentes buscam ajustar suas formas de pensar, perceber e agir às exigências objetivas desse mesmo campo. Por isso, enquanto espaços de 
relações em movimento, os campos apresentam aos seus agentes a possibilidade de travarem uma luta, por meio da qual constroem processos visando à disputa pelo poder em seu interior. Ainda para o autor, as relaçóes objetivas que configuram o campo podem ser de aliança el ou conflito, de concorrência e/ou de cooperação entre posiçôes diferenciadas, socialmente definidas e independentes das características dos agentes que o ocupam.

Em função do exposto, neste trabalho o campo está sendo concebido como um espaço social dotado de estrutura própria - relativamente autônoma sobre outros campos sociais - e de objetivos específicos que lhe garantem uma lógica particular de estruturação e funcionamento.

Apoiando-se no conceito de campo, proposto por Bourdieu (1983), o presente trabalho parte da premissa de que o campo da educação superior brasileira, como qualquer outro, revela uma lógica de funcionamento e um objeto próprio de grande interesse para aqueles que dele fazem parte, como, por exemplo, os gestores das IES, entrevistados para a pesquisa.

Nesse cenário de luta, como política pública concebida como a materialidade do Estado ou o "Estado em ação" (Azevedo, 2004), a avaliação da qualidade da educação superior continua com grande visibilidade, tomando como referência a relação entre Estado e políticas definidas para o setor.

Fisionomia da qualidade na educação superior do Distrito Federal na ótica dos gestores

Nos últimos dez anos, à semelhança do cenário nacional, a educação superior do DF vem passando por um considerável processo de expansão, notadamente no setor privado. Em 1996, havia apenas 13 IES locais e, dez anos depois, em 2006, 75 (INEP, 2008). Tal aumento corresponde a $477 \%$, ao passo que, em termos nacionais, foi de $146 \%$, no mesmo período. No último ano mencionado, 73 (97\%) das IES do DF eram de natureza privada e apenas duas eram públicas. Com essa configuração, as instituições que compõem a rede local "(...) são distintas em termos de propostas, vocações, marcas, produtos e serviços que possibilitam o atendimento à demanda" (Sousa, 2003, p. 256). 
O estudo ora apresentado considera que nesse campo, como em qualquer outro, ocorrem lutas que assumem características semelhantes às de um jogo e que exigem, ao mesmo tempo, cumplicidade e concorrência (Bourdieu, 1983). Para realizá-lo, foram selecionadas 16 IES, uma pública e as demais de natureza privada - duas universidades, dois centros universitários, duas faculdades integradas e dez estabelecimentos isolados -, obedecendo aos seguintes critérios: a) natureza administrativa; b) organização acadêmica; c) localização; d) ano de criação. Essas instituições são identificadas, ao longo da análise, com letras de A a P.

Os sujeitos da pesquisa foram os fundadores e/ou dirigentes das IES selecionadas - reitor, diretor-presidente, diretor acadêmico, diretor geral - sendo três do sexo feminino (19\%) e treze do masculino (81\%). Quanto à trajetória acadêmica, nove deles (56\%) realizaram estudos em nível de doutorado.

A coleta dos dados ocorreu no último trimestre de 2006 e primeiro de 2007, privilegiando: a) entrevistas semiestruturadas, pois a conversa ajuda a afastar determinada censura, que "(...) nos impede de responder, através da escrita, questões que, do ponto de vista profissional, possam parecer triviais e inaceitáveis" (Bourdieu, 1990, p. 10); b) análise documental, considerando que os dados obtidos por meio dessa técnica admitem a busca em quaisquer materiais escritos que sirvam de fonte de informação acerca do comportamento humano (Phillips, 1987).

A análise dos dados coletados permite afirmar que a grande maioria dos entrevistados compreende a política de educação superior, da década de 1990 e da atual, como "democrática". Assim, mostrou-se subjacente à fala dos atores certo consenso de que a expansão da educação superior, verificada no período entre 1996 e 2006, foi positiva:

A expansão do ensino superior no Distrito Federal, particularmente, foi boa. Ela trouxe uma nova visão para o ensino superior, que antes era dominado por três ou quatro instituições e hoje devem ter em torno de setenta instituições de ensino no DF. (Gestor IES A)

(...) é uma vantagem porque amplia a questão da concorrência. Isso, consequentemente, vai forçar o meu concorrente a mostrar um ensino de qualidade para o aluno dele (...). (Gestor IES B) 
Qualidade na educação superior: lugar e sentido na relação público-privado

Porém, ao relacionar o mesmo processo expansionista à questão da qualidade, alguns dos entrevistados mostraram-se reticentes, fazendo determinadas restrições:

(...) essa expansão prejudicou muito a qualidade (...) as instituições que foram criadas também não tinham os recursos adequados para poder atender de imediato o que o MEC exigia. (Gestor IES C)

Muitos aventureiros que estavam no ramo de posto de gasolina, no ramo de supermercado, acharam que o ensino superior era mais uma vertente de arrecadar e angariar fundos, recursos e multiplicar seus capitais. (Gestor IES D)

Houve um crescimento acelerado, mas um crescimento muitas vezes sem qualidade e com preço alto. Crescimento duvidoso e isso agora terá reflexos. (Gestor IES E)

A maioria absoluta dos entrevistados $(81 \%)$ entende que a política educacional vem apresentando, também, parâmetros avaliativos para a expansão que continua a se verificar no sistema, estimulando, de certa forma, a melhoria do desempenho das IES, especialmente as particulares. Fica subjacente à fala deles que os mecanismos avaliativos, definidos pelo Sistema Nacional de Avaliação da Educação Superior (SINAES), levantam a expectativa de que as IES que não atendam aos critérios de qualidade venham a perder determinadas posições na educação superior local. Contudo, parecem não perceber ou considerar que a presença "(...) de milhares de estudantes matriculados nas instituições de ensino superior de mais baixa qualidade pode representar um poderoso inibidor para que a avaliação desenvolvida pelo SINAES seja efetiva e consequente (...)" (Cunha, 2007, p. 827).

Retomando a ideia de que a qualidade é condição indispensável à permanência das IES no campo da educação superior do DF, são ilustrativas as seguintes falas:

(...) as instituições [IES] vão ter que oferecer o melhor e só vai permanecer nesse mercado quem pensar no melhor e, com isso, muitas sairão. (Gestor IES F)

Quem tiver a qualidade vai sobreviver, embora em um país como o nosso, que tem muitas desigualdades, às vezes uns passam certo tempo se enganando com relação à qualidade, mas isso, mais dia ou menos dia, aflora. (Gestor IES G)

Tudo indica que a alternativa mais razoável seria as IES se adequarem aos mecanismos de avaliação definidos para o setor, visto que a 
avaliação é percebida, pela maioria dos entrevistados, basicamente como um mecanismo de controle de qualidade para conter a expansão que o próprio Estado estimulou nos últimos anos, particularmente na esfera privada. Assim, os atores tendem a não perceber a avaliação da educação superior como um processo que vise, fundamentalmente, coletar subsídios que concorram para o aperfeiçoamento do trabalho das IES, com foco na melhoria da qualidade do ensino. Subjaz às falas registradas uma premissa que se aproxima da tese de Sousa (2003, p. 136), segundo a qual, em razão da luta que se estabelece entre as IES privadas locais do DF, desde a segunda metade da década de 1990, “(...) tenderão a permanecer no campo apenas aquelas instituições que associarem, bem, competência gerencial à qualidade do ensino que oferecem".

Com o propósito de imprimir um sentido à qualidade do trabalho de suas respectivas IES, os entrevistados deixam transparecer a ideia de que a qualidade é algo do qual não se pode abrir mão. Porém, embora a qualidade tenha sido o elemento frequentemente apontado pela totalidade dos gestores das IES, como condição sine qua non para todas que desejem continuar atuando no campo do qual fazem parte, nem sempre fica clara a concepção de qualidade de vários dos atores:

(...) qualidade nada mais é do que atualização dos currículos, melhoria do nível instrucional (...) melhor seleção dos professores, atendimento às exigências do MEC etc. (Gestor IES $\mathrm{H}$ )

Vou dar três exemplos [de qualidade]. O primeiro é a questão do preço: ser acessível ao nível de poder aquisitivo menor (...). Ano passado e início desse não cobramos taxa de inscrição (...). E o terceiro exemplo é o trote solidário (...). No final do mês vamos para a doação de sangue. (Gestor IES I)

Você pega 2.400 horas e divide isso em quatro anos (...). Agora, você pega 2.400 horas e adequa isso a três anos: põe aulas aos sábados, começa a aula trinta minutos mais cedo - às dezenove horas, ao invés de dezenove e vinte - e termina vinte e duas e cinquenta, ao invés de vinte e duas e trinta, e atende as 2.400 horas. Você está prejudicando a qualidade? Não está de forma alguma! (Gestor IES J)

A análise dos dados permite inferir que a grande maioria das IES tem procurado produzir um discurso focado na qualidade, visando distinguir-se das demais. Entretanto, muitas delas não apontaram um diferencial de natureza acadêmica para destacá-las das concorrentes, nem identificaram elementos que concorrem para construir essa qualidade. 
Qualidade na educação superior: lugar e sentido na relação público-privado

Frequentemente, seus gestores evidenciaram, por exemplo: a) a estrutura física de suas respectivas escolas, geralmente considerando-a superior a de várias concorrentes; b) pouca clareza a respeito do peso do elemento acadêmico para a construção da qualidade em seus estabelecimentos; c) a ideia de qualidade associada ao "atendimento personalizado ao aluno", como expõem dois entrevistados:

Hoje, a faculdade tem praticamente 2.500 alunos e a gente passa uma semana todinha conversando com eles no auditório (...) aqui ele é partícipe, porque nós colocamos isso no estudante (...) ele é tratado em sua individualidade, é tratado pelo nome. (Gestor IES K)

Aqui o aluno é tratado de forma diferenciada (...) de maneira especial. Aqui, a direção conhece aluno por aluno (...) às vezes é até estranho, mas a gente acompanha o aluno no todo. (Gestor IES L)

Também é possível inferir, pelos relatos colhidos, que a política educacional atual, no que tange à avaliação/qualidade, tem sugerido às IES a comprovação de determinada competência, caso desejem permanecer no campo no qual estão inseridas, como revela a fala a seguir:

O MEC é o órgão que autoriza e credencia as instituições. Na autorização, ele acredita no seu projeto, mas na hora do reconhecimento ele já vai observar se você fez o seu dever de casa. Então, muitas não estão fazendo o dever de casa e nem vão fazer (...). (Gestor IES M)

Para Bourdieu (1990), o interesse é, ao mesmo tempo, condição e funcionamento de um campo, à medida que "(...) é o que estimula as pessoas, o que as faz concorrer, rivalizar, lutar, e produto do funcionamento do campo" (p. 127). Com base nessa ideia, pode-se afirmar que, ao expressarem suas percepções acerca da qualidade defendida pela atual política para a educação superior, os atores revelaram-se dispostos a participar do jogo realizado, reconhecendo a qualidade como elemento intrínseco a esse jogo.

Cabe destacar, também, que na percepção do dirigente da universidade pública local, ainda que as IES particulares considerem o mercado elemento importante para estruturar suas práticas, elas acabam adotando a instituição sob sua direção como referência para planejar o próprio trabalho. Por outro lado, um gestor destacou, ao mesmo tempo, o foco da instituição sob sua direção, em relação à qualidade, bem como uma dificuldade prática para garanti-la: 
O que temos de defender é que a expansão e a inclusão não precisam comprometer a qualidade. (...) como gestores, somos responsáveis para que isso não se altere de maneira a perder qualidade, a relevância e o impacto social [mas] não somos tão competitivos como no passado (...). Os professores pedem licença para trabalhar em IES privadas (...). Eles não esperam enriquecer na universidade, mas esperam ter um padrão. (Gestor IES L)

Ao concluir a análise das falas dos entrevistados, é relevante ressaltar um ponto comum expresso em suas concepções sobre qualidade na educação superior. Em geral, os gestores pesquisados - tanto aqueles relacionados à esfera privada quanto o representante do setor público compreendem que as escolas sob sua direção têm estruturado suas práticas institucionais a partir de duas grandes dimensões: (i) as diretrizes da política educacional formulada mais recentemente para avaliar a educação superior; (ii) a dinâmica assumida pela esfera privada, em função de sua acentuada expansão e diversificação, ocorridas notadamente a partir da segunda metade da década de 1990, no Brasil e no Distrito Federal (Sousa, 2003, 2006).

Por último, destaca-se que, mantendo coerência com a heterogeneidade presente no sistema de educação superior brasileiro como um todo, o segmento privado local apresenta um grupo complexo de estabelecimentos que se diferenciam, também, em função dos distintos objetivos e valores perseguidos pelas instituições que o compõem. Nessa lógica, corroboram uma tendência verificada também em nível nacional, visto que várias dessas instituições “(...) definem suas estratégias em função do ensino e, especialmente, do ensino profissional. Para essas instituiçôes, a métrica acadêmica tradicional, que conforma nossa legislação, é inadequada" (Balbachevsky, 1999, p. 141).

\section{Considerações finais}

O objetivo deste artigo foi analisar o sentido e o lugar da qualidade na educação superior, considerando a relação público-privado, tomando como referência as percepçóes dos dirigentes de um grupo de dezesseis IEs localizadas no DF, a respeito da temática.

Ao procurar compreender o sentido que os entrevistados atribuem ao conceito de qualidade produzido pelas instituições sob sua gestão, 
a análise buscou apoio na premissa de Bourdieu (1990) de que as representações dos indivíduos variam de acordo com sua posição e interesses associados a elas. Esse princípio remeteu à ideia de que tanto os atores selecionados quanto suas respectivas IES estão inseridos em um contexto sócio-histórico específico e dotados de recursos e capitais de tipos variados.

O universo dessas instituições revelou que elas são bastante heterogêneas, corroborando a tendência verificada na morfologia institucional da educação superior brasileira. Mantendo coerência com essa realidade, o segmento privado do DF apresenta um grupo complexo de estabelecimentos que se diferenciam, também, em relação aos distintos objetivos, valores e concepções de qualidade das instituições que o compóem.

Na última década, a educação superior no país e no DF sofreu rápidas transformações provocadas por inúmeros fatores de natureza específica desse campo e outros de natureza direta e indiretamente a ele relacionados. A despeito desse cenário de mudanças, diversos atores e entidades mostram-se de acordo, em relação a alguns problemas enfrentados por esse nível de educação, como, por exemplo, os mecanismos de controle da qualidade do ensino ofertado.

O estudo revelou, também, que as IES privadas investigadas estão seguindo uma tendência nacional, concebendo suas propostas, em grande parte, segundo a lógica da concorrência do mercado. Além disso, há pouca clareza conceitual e metodológica, no que se refere a determinado padrão de qualidade a ser perseguido pelas instituições.

Considerando os dados analisados, conclui-se que: a) a preocupação com a qualidade manteve-se presente, de maneira muito forte, na totalidade das falas dos entrevistados; b) a qualidade mostra-se associada, em vários casos, à ideia de que é preciso deixar que o "mercado educacional" se organize pelas suas próprias leis e regras, visando a obrigar os estabelecimentos a primarem pela qualidade dos serviços que prestam; c) alguns gestores parecem não acreditar que todas as IES privadas locais desejam criar, de fato, um padrão de qualidade que as diferencie de suas concorrentes na oferta da educação superior.

Recebido em novembro de 2007 e aprovado em agosto de 2008. 


\section{Referências}

AZEVEDO, J.M.L. A educação como política pública. 3. ed. Campinas: Autores Associados, 2004.

BALBACHEVSKY, E. A profissão acadêmica no Brasil: as múltiplas facetas do nosso sistema de ensino superior. Brasília, DF: FUNADESP, 1999.

BONDIOLI, A. O projeto pedagógico da creche e a sua avaliação: a qualidade negociada. Campinas: Autores Associados, 2004.

BOURDIEU, P. Questôes de sociologia. Rio de Janeiro: Marco Zero, 1983.

BOURDIEU, P. Coisas ditas. São Paulo: Brasiliense, 1990.

BOURDIEU, P. O poder simbólico. 2. ed. Rio de Janeiro: Bertrand Brasil; Lisboa: DIFEL, 1998.

BRASIL. Constituição (1988). Constituição da República Federativa do Brasil. Brasília, DF: Senado Federal, 1988.

BRASIL. Lei n. 9.394, de 20 de dezembro de 1996. Dispõe sobre as Diretrizes e Bases da Educação Nacional. Brasília, DF, 1996.

BRASIL. Lei n. 10.172, de 9 de janeiro de 2001. Aprova o Plano Nacional de Educação e dá outras providencias. Diário Oficial da União, Brasília, DF, 10 jan. 2001.

BRASIL. Lei n. 10.861, de 14 de abril de 2004. Institui o Sistema Nacional de Avaliação da Educação Superior - SINAES e dá outras providencias. Diário Oficial da União, Brasília, DF, 15 abr. 2004.

BRASIL. Ministério da Educação. Instituto Nacional de Estudos e Pesquisas Educacionais. Sinopse estatística da educação superior: censo 2006. Disponível em: http://www.inep.gov.br/superior/censosuperior/sinopse/default.asp. Acesso em: 25 fev. 2008.

CATANI, A.M.; OLIVEIRA, J.F. Educação superior no Brasil: reestruturação e metamorfose das universidades públicas. Petrópolis: Vozes, 2002. 
CUNHA, L.A. O desenvolvimento meandroso da educação brasileira entre o Estado e o mercado. Educação \& Sociedade, Campinas, v. 28, n. 100, p. 809-829, out. 2007.

DOURADO, L.F.; OLIVEIRA, J.F; SANTOS, C.A. A qualidade da educação: conceitos e definições. Brasília, DF: INEP, 2007.

ENGUITA, M. O discurso da qualidade e a qualidade do discurso. In: Gentili, P.; Silva, T.T. (Org.). Neoliberalismo, qualidade total e educação. 2. ed. Petrópolis: Vozes, 1995. p. 93-110.

GUADILLA, C.G. Tensiones y transiciones. Venezuela: Cendes, 2002.

MARTINS, C.B. O ensino superior privado no Distrito Federal. Cadernos de Pesquisa, São Paulo, n. 102, p. 157-186, nov. 1997.

OLIVEIRA, J.F.; DOURADO, L.F. Educação superior: o público e o privado na produção do trabalho e da vida acadêmica. In: AdRIÃo, T.; Peroni, V. (Org.). O público e o privado na educação: interfaces entre Estado e sociedade. São Paulo: Xamã, 2005. p. 57-80.

PHILIPS, B.S. Pesquisa social. 3. ed. Rio de Janeiro: Agir, 1987.

SOUSA, J.V. O ensino superior privado no Distrito Federal: uma análise de sua recente expansão (1995-2001). 2003. 293f. Tese (Doutorado) - Departamento de Sociologia, Universidade de Brasília, Brasília, DF.

SOUSA, J.V. Restrição do público e estímulo à iniciativa privada: tendência histórica no ensino superior brasileiro. In: SILVA, M.A.; SiLvA, R.A. (Org.). A ideia de universidade: rumos e desafios. Brasília, DF: Líber, 2006. p. 139-178. 